\title{
10 health stories that mattered: Aug. 30-Sept. 5
}

- The number of applications for medical marijuana licences recently topped 1000, but Health Canada has issued only two licences in the past three months. Of the 1009 applications received by Aug. 25, almost half (462) were returned as incomplete, 201 were rejected, 32 were withdrawn, and the rest are still being assessed.

- GlaxoSmithKline will have a shortfall of about $30 \%$ on Canada's order for flu vaccine for 2014-15. The shortfall of two million doses has been attributed to production problems at the company's facility in Ste. Foy, Quebec.

- More women at high risk of breast cancer pursued genetic testing for mutated BRCA genes after actress Angelina Jolie announced she had a preventive double mastectomy, according to research out of Sunnybrook Hospital's Odette Cancer Centre in Toronto. The "Angelina effect" resulted in a $90 \%$ increase in referrals for genetic counselling (487 to 916), a 105\% increase in patients who qualified for genetic testing (213 to 437) and a $110 \%$ increase in patients found to have a mutated BRCA gene (29 to 61 ).
- At least nine Canadians will be among the 200 experts meeting in Geneva, Switzerland, to discuss how best to use Ebola drugs and vaccines. The meeting, organized by the World Health Organization, will explore questions such as how to accelerate registration of the experimental treatments and how the limited amounts available should be divvied up.

- New Brunswick's Chief Medical Officer of Health is heading to Nigeria to lend her expertise to addressing the Ebola outbreak in West Africa. Dr. Eilish Cleary, who will visit the region for 10 weeks, will not be in direct contact with patients but will be responsible for managing policies regarding the outbreak.

- Manitoba has promised to make a donation to assist agencies fighting Ebola in West Africa. The announcement was made at a rally organized by members of Winnipeg's Liberian community to raise awareness of the humanitarian needs in Liberia, which has been affected by the Ebola outbreak.

- An Ontario resident who had visited West Africa was isolated and tested for the Ebola virus after reporting to a hospital in the Niagara Region with flu-like symptoms. Patients in Montréal, Ottawa, and Brampton, Ontario, have recently tested negative for Ebola.

- Fees for malpractice protection are set to almost double for physicians outside of Ontario and Quebec. According to the Canadian Medical Protective Association, which provides assistance to doctors facing lawsuits, fees will increase because the amounts of money awarded to patients in courts have risen sharply.

- The number of children and youth waiting for mental health outpatient and outreach services in Ottawa has increased from 1082 to 1195 in the past year. Wait times can be as long as 8-10 months at the Children's Hospital of Eastern Ontario and up to a year at The Royal, a mental health care and research facility.

- Alberta Health Services has launched a website to fight misinformation about vaccination. The website addresses safety concerns, explains how vaccines work and provides a downloadable vaccination schedule. — Roger Collier, CMAJ

CMAJ 2014. DOI:10.1503/cmaj.109-4895 